\title{
Student Attitudes towards Computer Assisted Learning: Scaling -up Medical Education in a Poor Setting
}

\author{
Jerome Addah \\ Department of Community Medicine, School of Medicine and Health Sciences \\ University for Development Studies, Tamale Ghana West Africa
}

Post Office Box TL 1883

\begin{abstract}
The economic, infrastructural, and manpower challenges peculiar to poor settings pose daunting obstacles to quality medical education and healthcare delivery in those settings. The purpose of the current study therefore was to determine from the perspective of students how to effectively incorporate information communication technology (ICT) in to the medical curriculum to help improve tuition and scale up training in a Ghanaian Medical School, and concluded that blended instructional models may be more suitable.
\end{abstract}

\section{Keywords}

Computer Assisted Instruction, Medical Education

\section{INTRODUCTION}

Sub - Saharan Africa as a regional block faces daunting challenges, its countries are poor, basic health infrastructure is limited, the burden of disease is disproportionately high, and shortage of health manpower is endemic [1]. An estimated 145,000 physicians (about $5 \%$ of the physician population in Europe) in Sub-Saharan Africa are serving a population of 821 million (which is more than the population of Europe), with a physician to population ratio of 18 to 100,000 [2]. Ghana's physician to population ratio of 9 to 100,000 [3], compared with, countries such as India (60 per 100,000), Brazil (170 per 100,000), and France (370 per 100,000) [2] is much poorer. Several factors account for the observed low physician to population ratio in Sub - Saharan Africa, a modest output of students by a small number of medical schools, coupled with emigration of many graduates to other countries or continents are the most prominent ones. Most countries are currently implementing a so-called educate and retain strategy, this strategy though laudable is currently facing some headwinds in most countries, in one instance, the non- availability of well-established tracking systems by governments and medical schools is making it difficult for them to monitor the whereabouts of graduates[4]. Also many medical schools are finding it difficult to cope with increasing enrolment numbers. Ghana like many other countries in Sub Saharan Africa has scaled up medical education as part of efforts towards increasing the number of doctors, the establishment of the School of Medicine and Health Science (SMHS) at the University for Development Studies (UDS) in Tamale occurred as a result of these efforts. At the SMHS shortage of faculty is widespread, and problematic, the school is currently experiencing shortage of faculty in both basic and clinical sciences. Small salaries, limited career options, heavy teaching loads, growing enrolment, and absence of equipment and support staff, have contributed to making the school unattractive to prospective faculty. In the face of the social, scientific, and pedagogical challenges noted above information communication technology has been proposed for use by medical educators to improve the efficiency, and effectiveness of educational interventions [5]. Educational content in medical schools especially in the developed world, is increasingly been delivered by means of computer assisted learning (CAL) [6], efficiency, portability, consistency, and effectiveness have all been cited as reasons for using this technology in the medical school environment[7, 8], CAL is expected to foster collaborative learning in the medical knowledge domains[9]. CAL is defined as supplementing regular lectures and lab activities with computer activities during or surrounding class time [10]. Using appropriate solutions CAL has been used to provide distributed teaching in the health sector in Africa, within constraints of bandwidth, cost, and power supply [11]. Resau Afrique Francophone de Telemedicine (RAFT), provides 2 hours of continuing medical education, at low bandwidth to a network of Francophone participants in 15 West African countries[12]. The African Medical and Research Foundation (AMREF) is involved in a programme to improve the qualifications of nurses in Kenya through a mix of face to face session and self - paced CAI [13]. Widespread adoption of CAL in Africa is hampered by technology, economic, as well as sociocultural factors. Africa continues to lag behind the rest of the world in the provision and availability of the ICT infrastructure that forms the backbone for the application of CAL applications, poor download speeds particularly in East and West Africa limit the potential of internet resources (such as videos, sound and other large downloads) [14]. The development of CAI applications is also limited by time and cost considerations[15-17]. Because of the time, and cost factors inherent in the development/deployment of CAI programs the introduction of CAL requires careful consideration [18], it has been suggested that their development be strongly linked to learning theories and instructional strategies [19]. Research has shown that personality type, learning style[20,21], and in the case of first year students entry level competence in ICT [22] influence utilization of CAL applications, Dorup [23] reported that among first - year students, $46.0 \%$ of males were in favour of replacing "traditional teaching with use of computers if possible" while only $22 \%$ of females agreed with this statement. It is also known that the results of media comparative studies are severely confounded [23-25], the discordance in the results of such studies have encouraged calls for using blended learning models as alternatives to single delivery media programs[26, 27]. In view of this, it has been argued that [28], current research should focus on comparing different formats of CAL to determine which are appropriate and under what conditions or circumstances. Within this context grey areas still exist, for instance it is not clear whether adaptations of CAL formats in response to individual differences such as computer experience, ICT skill levels, within the constraints of cost, and time would elicit the greatest acceptance among students without compromising knowledge particularly in a poor setting. The goal of the 
current study therefore is to provide evidence based information that would inform curriculum development suitable for a poor setting within a framework of effective cognitive structuring.

\section{METHODS AND MATERIALS}

This study is the result of a survey among first - year students in a Ghanaian Medical School using a questionnaire designed to investigate entry - level skills in ICT, and student attitudes towards incorporating ICT into the medical school curriculum. Completion of the questionnaire was taken as consent to participate in the study.

\subsection{Setting and Participants}

A cohort of 250 students of the School of Medicine and Health Sciences, University for Development Studies, Tamale, Ghana. The non - response rate was approximately $4 \%$. The students were informed of the Purpose of the study, the requirement to complete a questionnaire, and the general content of the questionnaire. They were also told that their participation in the study was voluntary and that no personal identifiable information was going to be taken. The University for Development studies, Tamale is located in the north of Ghana and is one of the third generations of tertiary Universities to be established in the country. At the moment, the medical school has no public access to computers for medical students, it however provides broadband internet access for staff and students, and computers are not available in the library for students to use, currently the University has eight faculties spread throughout four campuses. All students at the medical school take a mandatory course in basic ICT skills (introduction to computers, and the internet, windows, Microsoft application programs) at the beginning of their University studies.

\subsection{Survey Instrument}

The students were asked the following questions pertaining to: instructional methods, educational tools, ICT skill types: Basic (able to do basic word processing and use the internet), Intermediate (Have mastered the basics and have developed additional skills, including the use of different software programs), Advanced (Knowledgeable about hardware and software), ability to perform certain task with computers. A drafted version of the questionnaire was administered to students $(\mathrm{n}=100)$ in June, 2011. Internal reliability (Cronbach's alpha) obtained from combining items with ordinal responses was $0.82(95 \% \mathrm{CI})$ for intra class correlation coefficient; 0.79 to 0.88 . The questionnaires were administered to the students who consented to participate in the study.

\subsection{Data Analysis}

Statistical analysis was performed using STATA (version 11.0, StataCorp. 2009). In order to identify medical students' preference and attitudes, an analysis of frequencies of items derived from responses to questions related to 'instructional methods', 'educational tools' and ICT skills was undertaken. Categorical variables were analyzed using chi-square.

\section{RESULTS}

All together 142 males and 97 female students aged 18 and above, in their first year at the School of Medicine and Health Sciences of the University for Development Studies, Tamale, participated in the questionnaire survey (Table 1). The result of the survey indicated that majority of responding students had the following characteristics: within the age group 18 and
22 years $(69.5 \%)$, males $(59.4 \%)$, expressed preference for a live lecture $(58.6 \%)$ where they could sit in with the opportunity to ask questions, $68.6 \%$ of them were willing to comply with a requirement to bring a laptop computer to class to access lecture hand outs and take notes, $74.1 \%$ of them were using the internet to supplement their learning. A little less than half of them $(32.2 \%)$ said they would like the opportunity to download their lecture notes from the website to maximize their learning as can be seen from Table 1 .

Table 1 Participant demographics and characteristics ( $\mathbf{N}=\mathbf{2 3 9})$

\begin{tabular}{|c|c|}
\hline & $\mathrm{n}(\%)$ \\
\hline \multicolumn{2}{|l|}{ Age } \\
\hline $18-22$ & $166(69.5 \%)$ \\
\hline $23-27$ & $53(22.2 \%)$ \\
\hline $28-32$ & $8(3.3 \%)$ \\
\hline $33-37$ & $6(2.5 \%)$ \\
\hline$>47$ & $6(2.5 \%)$ \\
\hline \multicolumn{2}{|l|}{ Gender } \\
\hline Female & $97(40.6 \%)$ \\
\hline Male & $142(59.4 \%)$ \\
\hline \multicolumn{2}{|l|}{ Teaching Method } \\
\hline \multicolumn{2}{|l|}{ Lecture } \\
\hline Live & $140(58.6 \%)$ \\
\hline Video & $19(7.9 \%)$ \\
\hline \multicolumn{2}{|l|}{ Lecture Support Material } \\
\hline \multicolumn{2}{|l|}{ Traditional } \\
\hline Paper (Handout) & $3(1.3 \%)$ \\
\hline \multicolumn{2}{|l|}{ Electronic } \\
\hline Website & $77(32.2 \%)$ \\
\hline \multicolumn{2}{|l|}{ Educational Tools } \\
\hline $\begin{array}{l}\text { Should not be required to } \\
\text { own a computer }\end{array}$ & $73(30.5 \%)$ \\
\hline $\begin{array}{l}\text { laptop computer should be } \\
\text { required for class }\end{array}$ & $164(68.6 \%)$ \\
\hline would still like to buy a textbook & $96(40.2 \%)$ \\
\hline \multicolumn{2}{|l|}{ Web Site Use } \\
\hline $\begin{array}{l}\text { I use the internet to supplement } \\
\text { my learning }\end{array}$ & $177(74.1 \%)$ \\
\hline $\begin{array}{l}\text { I don't use the internet to } \\
\text { supplement my learning }\end{array}$ & $21(8.8 \%)$ \\
\hline
\end{tabular}

Bases on the studies designated ICT skill categories (basic, intermediate, and advanced), $45.2 \%$ of responding students rated their ICT skills as basic, $51.6 \%$ as intermediate, while only $3.3 \%$ of them rated their ICT skills as advanced (Table 2). More females than males rated their ICT skills as basic, while more males rated their ICT skills as either intermediate or advanced, indeed all the students who rated their ICT skills as advanced were males.

Analysis of responds to questions related the use of ICT as a means of teaching revealed that, more students with basic ICT-skills opted for a live lecture(58.6\%), where they could sit in and ask questions compared to those with either intermediate or advanced ICT skills. Students who preferred viewing a videoed lecture later at their convenience were mostly those with intermediate ICT skills, no student with advanced ICT skills opted for this method of delivering a lecture. All the students who wanted their lecture notes in 
paper hand out format were students with basic skills, while those who preferred accessing or downloading their lecture notes from a website were students with advanced ICT skills $(62.5 \%)$, followed by those with intermediate skills (37.4\%), students who did not want to be required to own a computer were either having basic skills

$(38.0 \%)$ or intermediate ICT skills $(26.0 \%)$, no student with advanced ICT skills objected to been required to own a computer. Responding participants who did not object to been required to bring a laptop to class to access lecture hand outs and take notes were either having advanced ICT skills $(87.5 \%)$ or intermediate skills $(78.9 \%)$. All the students with advanced skills, together with $40.7 \%$ of those with basic ICT skills, and $35.8 \%$ of those with intermediate ICT skills said they would still buy a textbook even if they had an access to an electronic version of it. Use of the internet to supplement learning was done by all the students with advanced skills, as well as some of those having intermediate and basic skills (Table 2)

Table 2 Stratification of responding participants $(n=239)$ based on their self-assessed ICT skill levels.

\begin{tabular}{|c|c|c|c|c|c|}
\hline & $\begin{array}{c}\text { Total } \\
(\mathrm{n}=239)\end{array}$ & $\begin{array}{c}\text { Basic } \\
(\mathrm{n}=108)\end{array}$ & $\begin{array}{l}\text { Intermediate } \\
(\mathrm{n}=123)\end{array}$ & $\begin{array}{l}\text { Advanced } \\
(\mathrm{n}=8)\end{array}$ & P-value \\
\hline \multicolumn{6}{|l|}{ Age } \\
\hline $18-22$ & $166(69.5 \%)$ & $71(65.7 \%)$ & $89(72.4 \%)$ & $6(75.0 \%)$ & 0.5203 \\
\hline $23-27$ & $53(22.2 \%)$ & $29(27.0 \%)$ & $22(18.0 \%)$ & $2(25.0 \%)$ & 0.2571 \\
\hline $28-32$ & $8(3.3 \%)$ & $8(7.4 \%)$ & $0(0.0 \%)$ & $0(0.0 \%)$ & $* 0.0066$ \\
\hline $33-37$ & $6(2.5 \%)$ & $0(0.0 \%)$ & $6(4.9 \%)$ & $0(0.0 \%)$ & $* 0.0549$ \\
\hline$>47$ & $6(2.5 \%)$ & $0(0.0 \%)$ & $6(4.9 \%)$ & $0(0.0 \%)$ & $* 0.0549$ \\
\hline \multicolumn{6}{|l|}{ Gender } \\
\hline Female & $97(40.6 \%)$ & $59(54.6 \%)$ & $38(30.9 \%)$ & $0(0.0 \%)$ & $<0.0001$ \\
\hline Male & $142(59.4 \%)$ & $49(45.4 \%)$ & $85(69.1 \%)$ & $8(100.0 \%)$ & $<0.0001$ \\
\hline \multicolumn{6}{|l|}{ Teaching Method } \\
\hline \multicolumn{6}{|l|}{ Lecture } \\
\hline Live & $140(58.6 \%)$ & $72(66.7 \%)$ & $65(52.8 \%)$ & $3(37.5 \%)$ & 0.0487 \\
\hline Video & $19(7.9 \%)$ & $7(6.5 \%)$ & $12(9.8 \%)$ & $0(0.0 \%)$ & $* 0.4590$ \\
\hline \multicolumn{6}{|l|}{ Lecture Support Material } \\
\hline \multicolumn{6}{|l|}{ Traditional } \\
\hline Paper (Handout) & $3(1.3 \%)$ & $3(2.8 \%)$ & $0(0.0 \%)$ & $0(0.0 \%)$ & $* 0.1584$ \\
\hline \multicolumn{6}{|l|}{ Electronic } \\
\hline Website & $77(32.2 \%)$ & $26(24.1 \%)$ & $46(37.4 \%)$ & $5(62.5 \%)$ & 0.0170 \\
\hline \multicolumn{6}{|l|}{ Educational Tools } \\
\hline Should not be required to own a computer & $73(30.5 \%)$ & $41(38.0 \%)$ & $32(26.0 \%)$ & $0(0.0 \%)$ & 0.0234 \\
\hline laptop computer should be required for class & $164(68.6 \%)$ & $60(55.6 \%)$ & $97(78.9 \%)$ & $7(87.5 \%)$ & 0.0004 \\
\hline would still like to buy a textbook & $96(40.2 \%)$ & $44(40.7 \%)$ & $44(35.8 \%)$ & $8(100.0 \%)$ & 0.0016 \\
\hline \multicolumn{6}{|l|}{ Web Site Use } \\
\hline I use the internet to supplement my learning & $177(74.1 \%)$ & $62(57.4 \%)$ & $107(87.0 \%)$ & $8(100.0 \%)$ & $<0.0001$ \\
\hline I don't use the internet to supplement my learning & $21(8.8 \%)$ & $15(13.9 \%)$ & $6(4.9 \%)$ & $0(0.0 \%)$ & 0.0365 \\
\hline
\end{tabular}

As can be seen from table 3, differences in age among responding participants was generally significant, this was also true in respect of their self-assessed ICT skill levels. More females $(72.2 \%)$ preferred sitting in a live lecture as did males $(49.3 \%)$, while more males opted to watch a videoed lecture later at their convenience, these differences were significant. Interestingly only female students $(3.1 \%)$ wanted to have a paper format of a lecture hand out, whereas more males $(40.1 \%)$ than females $(20.6 \%)$ preferred accessing or downloading such a hand out from a website, again these differences were significant. Significantly more females than males: objected to been required to own a computer, were willing to buy a textbook even if they had an electronic copy of it, and were either using the internet to supplement their learning or not. Males were more willing than females to accept a requirement to use a laptop computer to access lecture hand outs and take notes. 
Table 3 - A contingency table describing the stratification of Participant characteristics and demographics by gender(n=239)

\begin{tabular}{|c|c|c|c|c|}
\hline & Total $(n=239)$ & $\begin{array}{c}\text { Female } \\
(\mathrm{n}=97)\end{array}$ & $\begin{array}{c}\text { Male } \\
(\mathrm{n}=142)\end{array}$ & P-value \\
\hline \multicolumn{5}{|l|}{ Age } \\
\hline $18-22$ & $166(69.5 \%)$ & $78(80.4 \%)$ & $88(62.0 \%)$ & 0.0024 \\
\hline $23-27$ & $53(22.2 \%)$ & $13(13.4 \%)$ & $40(28.2 \%)$ & 0.007 \\
\hline $28-32$ & $8(3.3 \%)$ & $0(0.0 \%)$ & $8(5.6 \%)$ & 0.0174 \\
\hline $33-37$ & $6(2.5 \%)$ & $6(6.2 \%)$ & $0(0.0 \%)$ & 0.0027 \\
\hline$>47$ & $6(2.5 \%)$ & $0(0.0 \%)$ & $6(4.2 \%)$ & 0.0403 \\
\hline \multicolumn{5}{|l|}{ Self-Assessed Skill Level } \\
\hline Basic & $108(45.2 \%)$ & $59(60.8 \%)$ & $49(34.5 \%)$ & $<0.0001$ \\
\hline Intermediate & $123(51.5 \%)$ & $38(39.2 \%)$ & $85(59.9 \%)$ & 0.0017 \\
\hline Advanced & $8(3.3 \%)$ & $0(0.0 \%)$ & $8(5.6 \%)$ & 0.0174 \\
\hline \multicolumn{5}{|l|}{ Teaching Method } \\
\hline \multicolumn{5}{|l|}{ Lecture } \\
\hline Live & $140(58.6 \%)$ & $70(72.2 \%)$ & $70(49.3 \%)$ & 0.0004 \\
\hline Video & $19(7.9 \%)$ & $3(3.1 \%)$ & $16(11.3 \%)$ & 0.0218 \\
\hline \multicolumn{5}{|l|}{ Lecture Support Material } \\
\hline \multicolumn{5}{|l|}{ Traditional } \\
\hline Paper (Handout) & $3(1.3 \%)$ & $3(3.1 \%)$ & $0(0.0 \%)$ & 0.035 \\
\hline \multicolumn{5}{|l|}{ Electronic } \\
\hline Website & $77(32.2 \%)$ & $20(20.6 \%)$ & $57(40.1 \%)$ & 0.0015 \\
\hline \multicolumn{5}{|l|}{ Educational Tools } \\
\hline Should not be required to own a computer & $73(30.5 \%)$ & $41(42.3 \%)$ & $32(22.5 \%)$ & 0.0011 \\
\hline laptop computer should be required for class & $164(68.6 \%)$ & $52(53.6 \%)$ & $112(78.9 \%)$ & $<0.0001$ \\
\hline would still like to buy a textbook & $96(40.2 \%)$ & $50(51.5 \%)$ & $46(32.4 \%)$ & 0.003 \\
\hline \multicolumn{5}{|l|}{ Web Site Use } \\
\hline I use the internet to supplement my learning & $177(74.1 \%)$ & $80(82.5 \%)$ & $97(68.3 \%)$ & 0.0142 \\
\hline $\begin{array}{l}\text { I don't use the internet to supplement my } \\
\text { learning }\end{array}$ & $21(8.8 \%)$ & $16(16.5 \%)$ & $5(3.5 \%)$ & 0.0005 \\
\hline
\end{tabular}

\section{DISCUSSION}

Overall 131 students reported having intermediate to advanced ICT skills which included basic word processing skills, use of the internet, the ability to use different software programs, knowledge of software and hardware, and the ability to troubleshoot and do advice or teach others, this number of students represent a proportionate proficiency of $55.0 \%$, this level of proficiency is consistent with the findings of other studies reporting that increasing numbers of students are entering medical school with greater ICT - related knowledge and experience than in the past $[6,20,22]$. This level of proficiency most likely is the result of deliberate policy [29] or the manifestation of a sociocultural phenomenon. The has been a greater emphasis at the presecondary and secondary levels following a government education sector wide policy directive that made ICT a taught and examinable subject, in response to worldwide trends and also as an acknowledgement of the critical role ICT can play in national development. This observed level of proficiency may also be attributed to a so called technological hype that has pervaded Ghanaian youth culture [29] and commence within the last five years or so, as a result of this what is trendy seems to be whether or not you know how to use a word processing software or a spread sheet application, while prospective employees are advised to have as part of their skill set proficiency in such computer application programs, irrespective of the job been sort for. This has encouraged the setting up of private schools offering short courses in ICT; most graduating secondary school students take advantage of these schools to acquire ICT skills.

Student satisfaction is one of the critical factors that need to be taken into account when considering the effectiveness of CAL, since they are the final consumers of such technology, within this context our findings suggest that majority of responding students may be satisfied with a live lecture given the large numbers who favored a live lecture as opposed to viewing a video recording of a lecture at their own convenience, this finding is in agreement with the findings of Schreider et al. [25]. Our results suggest that several factors may be accounting for this, such factors most likely are shaped by the relationship between technological and non- 
technological dimensions: for example it has been observed that overwhelmingly majority of the students who reported having basic skills opted for a live lecture instead of a video recording of a lecture, we also note this preference among students possessing the other skill types, furthermore no student with advanced skills indicated preference for a video recording of a lecture and more male students than females preferred a video recorded lecture, while majority of those who favored a live lecture were female students. Put together this findings suggest that the preference of responding students cannot be explained on the basis of ICT proficiency alone, we are inclined to believe that the overwhelming numbers favoring a live lecture may be due to attitudinal prejudices informed by their prior experience with live lectures [20], we did not enquire about prior experience of both teaching methods since the was no basis to do so, this is because face to face teaching is about the only instructional method in Ghanaian secondary schools. The prospects of changing time tested learning styles or techniques with the advent of technology may also be responsible for this aversion [24]. Sun et al. [21], also suggest that this observed aversion for technology among students may be due to anxiety.

The observed technological aversion among responding students in the face of the staff shortages and other challenges have far reaching implications for scaling up medical training at the SMHS and healthcare delivery in this part of Ghana. As mentioned elsewhere, staff shortage at the SMHS is problematic, particularly at the clinical level, in most clinical disciplines specialist are not available, the few who are there refuse to join the medical school on fall time due to low academic salaries compared with public sector doctors [4], relying on expatriate lectures has proved costly. The staff situation pose accreditation challenges while also severely restricting quality tuition[4]. In addition to the staff shortages the SMHS does not have hostel facilities on campus, and near clinical sites for students, students therefore often commute long distances to class, resulting in poor class attendance.

The catchment area where the SMHS is situated is one of the deprived and poverty stricken regions in Ghana, the region lags behind the rest of the country in all measurable health indicators, compounding the situation is the continuous refusal by doctors down south to take up postings in this part of the country. In view of this precarious state of affairs, the SMHS has as one of its mandates to produce the manpower needed to stem this deprecating health situation, since graduating doctors would be people who are already acclimatized with the environment and well aware of the need for their service and thus will be more inclined to stay back [4]. There is therefore an imperative need to develop innovative ways of solving the pedagogical challenges at the SMHS, without such and initiative stemming the AIDS epidemic or achieving the Millennium Development Goals (MDG) [4], especially MDG 5 whose realization in this part of the country is becoming illusive. From the foregoing it is clear that even though an overwhelming number of students prefer a live lecture to a video recorded one, in the mist of these challenges continuing to deliver lectures by means of face - to - face live lectures is no longer sustainable and also jeopardies efforts at scaling - up. We may have to temper these views with more pragmatic arrangements.

The deficits in staff together with the other pedagogical challenges serve as strong arguments for providing students with the possibility of bypassing old traditional methods of instruction and benefiting from the rapidly advancing developments in CAL. the advantages of CAL have been shown not to be consistent [18], in recognition of this, it has been asserted that CAL should not replace, but rather serve as a valuable adjunct to learning techniques such as textbooks, lectures, small group discussion, and problem - based learning $[18,23]$. The ambivalence seen in the results of the current study regarding student preferred teaching methods, and educational tools, is elucidated by this assertion. Curriculum developed using the synergistic combination of traditional teaching methods with techniques that harness the characteristics of non-attendance based distance teaching have been shown to facilitate active learning, decrease the number of hours of attendance and long term knowledge while avoiding problems that may arise as a result of exclusively non- attendance - based teaching [27]. Many medical schools are supplementing live lectures with video recorded lectures allowing students the option of attending a live lecture or watching a recorded lecture material on $\mathrm{CD}$ - ROM or online, at their own convenience [26]. Recent advancement in video accelerated technology has helped quill worries over bandwidth and playback time, this has encouraged their use by medical schools to aid the viewing of video recorded lectures [26] such tools allow students with varying knowledge levels, and learning styles to watch recorded lectures [7], at varying speeds without distorting the recording.

Within each skill group most students indicated that they were using the internet to supplement their learning, similarly a sizable proportion preferred accessing a lecture hand out over the internet than have it in a paper format, this findings suggest that an appropriate medical school curriculum may be one that provides students with the opportunity to use a Webbased educational approach $[6,18]$. Our findings further suggest that appropriate web-use skills may have to be built into such a curriculum to make it successful. The reported use of web - based resources by responding students may provide medical educators with an opportunity to use online interactive multimedia tools that facilitate different presentation formats (text, graphics, animation, etc.), to build teaching and learning activities on complex, authentic, and real-life learning materials, such multiple presentation formats have been shown to aid the development of a rich schema structure in long-term memory [9].

\section{CONCLUSION}

This study though based on a single school has established that in poor settings blended instructional models may be more favourable compared to single - media instructional methods for delivering lectures in a medical school environment. A discussion of how to design blended models that satisfy goals for student learning and professionalism, as well as how to satisfy the desire for community in medical education is beyond the scope of the current study, within this purview issues such as which instructional media or methods to use, how to incorporate the perspectives of faculty, etc. could be exploited in other studies.

\section{ACKNOWLEDGMENTS}

The students who willing participated in this study are greatly indebted, 


\section{REFERENCES}

[1] WHO. World health report 2006: Working together for health. Geneva. In; 2006. p. 1-209.

[2] Aff airs of the United Nations Secretaria. World population prospects: the 2008 revision. In; 2009.

[3] Africa Health HaSDIS. 2011 AfricaHuman Resources for Health Scorecard. In: Incorporating Skilled Health Personnel, Maternal Mortality, Reproductive Health and Female Life Expectancy at Birth; 2011.

[4] Kombe G, Mullan F, Frehywot, S, Omaswa, F, Buch, E, Chen, C, Greysen SR, Wassermann T, Abubakr DEE, Awases M, Boelen C, Marie MJ, Diomande, I, Dovlo, D, Ferro J, Haileamlak, A, Iputo, J, Jacobs, M, Koumaré, AK, Mipando, M, Monekosso GL,OlapadeOlaopa, EO, Rugarabamu, P, Sewankambo NK, Ross, H, Ayas H, Chale SB, Cyprien, S, Cohen, J, Haile-Mariam T, Hamburger, E, Jolley, L, Kolars, JC, , Neusy, AJ. Medical schools in sub-Saharan Africa. The lancent 12011;377: 1113 - 1121 .

[5] Ward JP GJ, Field MJ, Lehmann HP. Communication and information technology in medical education. Lancet 12001;357:: 792-96

[6] Candler C, Andrews MD. Technology in medical education: how the OU College of Medicine has used technology to enhance the medical education experience. J Okla State Med Assoc 12004;97: 8-10.

[7] Murphy R, Gray SA, Straja SR, Bogert MC. Student learning preferences and teaching implications. J Dent Educ. 1 2004;;68: 859-866.

[8] Steele DJ, Palensky JEJ, Lynch TG,Lacy NL, Duffy,SW. Learning preferences, computer attitudes, and student evaluation of computerised instruction. MEDICAL EDUCATION 12002;;36: 225-232.

[9] Valcke M, De wever B. Information and communication technologies in higher education: evidence - based practices in medical education. Medical Teacher 12006;28: 40 - 48 .

[10] Kosmahl H. Instructional use of computers for entrylevel physical therapy education Journal of Pysical Therapy Education 11994;8: 25- 31.

[11] Mars M. Building the Capacity to Build Capacity in eHealth in Sub-Saharan Africa:The KwaZulu-Natal Experience. TELEMEDICINE and e-HEALTH 12012;18: 32 - 37.

[12] RAFT. Available at http://raft.hcuge.ch/ (Last accessed November 5, 2011). 12010.

[13] AMREF. E-Learning programme. 2011. Available at www.amref.org/info-centre/ amref-courses-trainingprogrammes/elearning-programme-/ (last accessed July $15,2011)$.

[14] Williams C, Pichforth E, Callaghan C. Computers, the internet and medical education in Africa. Medical education 12010;44: 485 - 488.
[15] Anderson J, Conley, LK Retention of anatomical detail. Journal of Physical Therapy Education 1 2000;14: : 4447.

[16] Kinney P, Keskula, D, Perry, J The effect of a computer assisted instruction program on physical therapy students. Journal of Allied Health 11997;26: 57-61.

[17] Thompson E. Computer-assisted instruction in curricula of physical therapy assistants. . Physical Therapy 11987;67: 1237-1239.

[18] Greenhalgh T. Computer assisted learning in undergraduate medical education. BMJ 12001;322: 40-4.

[19] Perlman C, Weston, C, Gisel, E A web-based tutorial to enhance student learning of activity analysis. Canadian Journal of Occupational Therapy 1 2005;72: : 153-163.

[20] McNulty J, Espiritu, B, Halsey, M, Mendez, M. Personality preference influences medical student use of specific computer-aided instruction (CAI). bmc Med Educ 12006;6.

[21] Sun P, Tsai , R, J, Fin., e G,.Chen , YY, Yeh , D. What drives a successful e - Learning? An empirical investigation of the critical factors influencing learner satisfaction. Computers \& Education 12008;50: 1183 1202.

[22] Scott CS, Schaad DC, Mandel LS, Brock DM, Kim S. Information and informatics literacy: skills, timing, and estimates of competence. Teach Learn Med 12000;12: 85-90.

[23] Dorup J. Experience and attitudes towards information technology among first-year medical students in Denmark: longitudinal questionnaire survey. J Med Internet Res 12004;6: e10.

[24] Hopkins R, Regehr, G. Wilson, TD. Exploring the changing Learning Environment of the Gross Anatomy Lab. Acad Med 12011;86: 883 - 887.

[25] Schreiber BE, . Fukuta, J,. Gordon, F. Live lecture versus video podcast in undergraduate medical education: A randomised controlled trial. BMC Med Educ 1 2010;10.

[26] Association of American Medical Colleges. AAMC OSR REPS' responses: 2007 survey on using multimedia technology to record lectures. Available at: (http://www.aamc.org/members/osr/surveys/multimedia. pdf). Accessed August 22, 2008.

[27] Singh H. Building Effective Blended Learning Programs Educational Technology 12003;43: 51 - 54.

[28] Cook DA. The Research we Still Are Not Doing: An Agenda for the study of Computer - Based Learning. Acad Med 12005;80: 541 - 547.

[29] ICT4AD. The Ghana ICT For Accelerated Development Policy. In; 2003. 